\title{
28 Research Square \\ Contamination of the slit-lamp breath shield under face-masking conditions: a prospective clinical study
}

\author{
Ken-ichi Sato ( $\sim$ vze04311@nifty.ne.jp) \\ Nikko Memorial Hospital https://orcid.org/0000-0003-0446-8017
}

\section{Short Report}

Keywords: Equipment contamination, slit lamp, masks, COVID-19, severe acute respiratory syndrome coronavirus 2

Posted Date: July 12th, 2021

DOl: https://doi.org/10.21203/rs.3.rs-640035/v1

License: (c) (1) This work is licensed under a Creative Commons Attribution 4.0 International License. Read Full License 


\section{Abstract}

Objective

Ophthalmologists have installed breath shields on slit-lamp microscopes to block droplets produced by patients and prevent infection with severe respiratory syndrome coronavirus 2 , the cause of the coronavirus disease 2019 pandemic. This study measured the contamination of one such shield used in clinical practice under face-masking conditions and examined its significance in preventing infection.

Methods

In this single-center prospective study, measurements were taken at an ophthalmology outpatient unit on 10 weekdays: 5 consultation days and 5 closed days. All patients were required to use face masks, including surgical masks, commercially available cloth masks, and homemade cloth masks. A breath shield, made of polyethylene terephthalate, was hung on the eyepieces of the slit-lamp microscope. Measurement areas of $5 \mathrm{~cm}^{2}$ were set on the patient-side surface of the shield, as well as on the slit-lamp table, where touching was not forbidden. Samples were collected after wiping with 78 vol\% ethanol at 9 a.m., at the beginning of office hours. Touching the shield was forbidden during office hours, and the samples were collected again at 5 p.m., at the end of office hours. The total amount of adenosine triphosphate + adenosine diphosphate + adenosine monophosphate was measured as an indicator of the degree of contamination.

Results

Contamination of the shield had increased by the end of office hours on the consultation days, although the $\mathrm{p}$-value from a paired $t$-test was slightly above 0.05 . In contrast, on days when the department was closed, no difference was observed in the level of contamination between morning and evening. Similarly, the slit-lamp table was significantly contaminated on consultation days, whereas there was no difference in contamination between morning and evening on closed days.

Conclusions

The results of this study indicate slight contamination of the slit-lamp microscope breath shield by droplets produced by patients who were wearing a face mask.

\section{Introduction}

Coronavirus disease 2019 (COVID-19), which is caused by infection with severe respiratory syndrome coronavirus 2 (SARS-CoV-2), is a potentially life-threatening disease, and was declared a pandemic by the World Health Organization on March 11, 2020 [1].

To perform examinations, ophthalmologists must work in close proximity to their patients, and this proximity increases their risk of infection with SARS-CoV-2 [2]. Using simulated experimental approaches, 
several studies have evaluated the effectiveness of various breath shields mounted on slit-lamp microscopes to block the spread of droplets from patients [3-8]. The present study measured the contamination of a shield used in clinical practice under face-masking conditions and examined its significance in preventing infection.

\section{Materials And Methods}

This single-center prospective study was conducted at Nikko Memorial Hospital in Muroran, Japan between November 28 and December 2, 2020.

Informed consent was obtained from all patients before their examination. The study adhered to the tenets of the Declaration of Helsinki and was approved by the ethics committee of Nikko Memorial Hospital.

Measurements were taken at an ophthalmology outpatient unit on 10 weekdays; outpatient care was provided on 5 days and the unit was not used on the other 5 days. All patients were examined by a single ophthalmologist.

All patients were required to wear a facial mask, including surgical masks, commercially available cloth masks, and homemade cloth masks.

A breath shield (Carl Zeiss Meditec, Tokyo, Japan) made of polyethylene terephthalate, was hung on the eyepieces of the slit-lamp microscope, and a measurement area of $25 \mathrm{~cm}^{2}$ was provided on the patientside of the shield (Fig. 1).

On each consultation day, the measurement area was wiped with 78 vol\% ethanol at 9 a.m., at the beginning of office hours. After waiting $5 \mathrm{~min}$ for the ethanol to completely evaporate, samples were collected. Immediately afterward, the area was cleaned with ethanol again. Touching the shield was forbidden during office hours. Samples were collected again at 5 p.m., at the end of office hours. Samples were also collected in the same way on each day when no outpatient care was provided. In addition, a measurement area of $25 \mathrm{~cm}^{2}$ was set on the table of the slit-lamp microscope (Fig. 1), where touching was not forbidden, and the degree of contamination was similarly examined on each day.

To obtain samples, the measurement area was rubbed with a sampling swab as widely as possible, 10 times back-and-forth longitudinally and 10 times laterally.

A hygiene monitoring kit consisting of LuciPac A3 Surface ${ }^{\circledR}$ and Lumitester PD-30 ${ }^{\circledR}$ (Kikkoman Biochemifa Company, Tokyo, Japan) was employed to measure the amount of adenosine triphosphate + adenosine diphosphate + adenosine monophosphate as an indicator of the degree of contamination.

Data analysis was performed using StatView 5.0 (SAS Institute, Inc., Cary, NC) with significance set at 5\%. Paired $t$-tests were used for statistical analysis. 


\section{Results}

The date of measurement, number of patients, degree of contamination, and $p$-values of paired $t$-tests for consultation days and closed days are shown in Tables 1 and Table 2, respectively. Contamination of the shield had increased by the end of office hours on each consultation day, although the $p$-value from the paired $t$-test was slightly above 0.05 . In contrast, on days when the department was closed, no difference was observed in the level of contamination between morning and evening. Similarly, the slit-lamp table was significantly contaminated on consultation days, whereas there was no difference in contamination between morning and evening on closed days.

Table 1

The total amount of adenosine triphosphate + adenosine diphosphate + adenosine monophosphate (relative light units) measured as an indication of the degree of contamination on consultation days

\begin{tabular}{|c|c|c|c|c|c|c|c|}
\hline \multicolumn{2}{|l|}{ Date } & $\begin{array}{l}\text { Nov. } 18 \text {, } \\
2020\end{array}$ & $\begin{array}{l}\text { Nov. 20, } \\
2020\end{array}$ & $\begin{array}{l}\text { Nov. } 27 \text {, } \\
2020\end{array}$ & $\begin{array}{l}\text { Nov. } 30 \text {, } \\
2020\end{array}$ & $\begin{array}{l}\text { Dec. } 2, \\
2020\end{array}$ & $\begin{array}{l}\text { P-value for } \\
\text { paired } t \text { test }\end{array}$ \\
\hline \multicolumn{2}{|c|}{$\begin{array}{l}\text { Number of } \\
\text { patients }\end{array}$} & 72 & 56 & 70 & 64 & 77 & \\
\hline \multirow[t]{2}{*}{ Shield } & $\begin{array}{l}9 \\
\text { a.m. }\end{array}$ & 14 & 14 & 8 & 13 & 13 & 0.056 \\
\hline & $\begin{array}{l}5 \\
\text { p.m. }\end{array}$ & 16 & 32 & 10 & 38 & 26 & \\
\hline \multirow[t]{2}{*}{ Table } & $\begin{array}{l}9 \\
\text { a.m. }\end{array}$ & 242 & 1244 & 353 & 287 & 353 & 0.004 \\
\hline & $\begin{array}{l}5 \\
\text { p.m. }\end{array}$ & 1450 & 3650 & 1289 & 2045 & 1805 & \\
\hline
\end{tabular}

Table 2

The total amount of adenosine triphosphate + adenosine diphosphate + adenosine monophosphate (relative light units) measured as an indication of the degree of contamination on days when no outpatient care was provided

\begin{tabular}{|c|c|c|c|c|c|c|c|}
\hline Date & & $\begin{array}{l}\text { Nov. } 17 \text {, } \\
2020\end{array}$ & $\begin{array}{l}\text { Nov. } 19 \text {, } \\
2020\end{array}$ & $\begin{array}{l}\text { Nov. 24, } \\
2020\end{array}$ & $\begin{array}{l}\text { Nov. 26, } \\
2020\end{array}$ & $\begin{array}{l}\text { Dec. 1, } \\
2020\end{array}$ & $\begin{array}{l}P \text {-value for a } \\
\text { paired } t \text { test }\end{array}$ \\
\hline \multirow[t]{2}{*}{ Shield } & $\begin{array}{l}9 \\
\text { a.m. }\end{array}$ & 11 & 16 & 28 & 13 & 32 & 0.145 \\
\hline & $\begin{array}{l}5 \\
\text { p.m. }\end{array}$ & 15 & 15 & 85 & 19 & 104 & \\
\hline \multirow[t]{2}{*}{ Table } & $\begin{array}{l}9 \\
\text { a.m. }\end{array}$ & 347 & 221 & 412 & 162 & 193 & 0.259 \\
\hline & $\begin{array}{l}5 \\
\text { p.m. }\end{array}$ & 264 & 374 & 442 & 269 & 249 & \\
\hline
\end{tabular}




\section{Discussion}

In this clinical study, patients wore masks made of various materials, including homemade cloth masks, commercial cloth masks, and surgical masks. Experimental studies comparing different mask materials have shown various results, with some showing no difference in the protective effect, and others showing the superiority of surgical masks $[9,10]$. In a simulation study with a breath shield installed on a slit-lamp microscope, Ong et al. reported that aerosols did not reach the examiners whether they wore a surgical mask or a cloth mask [7].

Based on Shah et al. [6], who suggested that patients wearing a surgical mask eject respiratory particles upward, the shield surface was considered to be contaminated by such droplets in the present study. Therefore, even when the patient is wearing a mask, a breath shield should be effective at blocking droplets produced by the patient during a slit-lamp examination.

There are several limitations to this study. First, to limit the risk of COVID-19 infection in both the examiner and the patients, all participants were required to wear a mask. Therefore, this study did not investigate the difference in contamination level between masked and unmasked conditions. Second, not only differences in the measurement location on the shield but also differences in the shape of the shield may alter the results, but neither were investigated. Furthermore, the results might vary according to changes in environmental conditions, including temperature, humidity, and airflow, none of which was monitored in this study. The study also did not examine whether differences in mask material affected the degree of contamination. Third, this study did not investigate whether the degree of shield surface contamination was related to the amount of adherent virus or the incidence of SARS-CoV-2 infection. Fourth, the statistical power was insufficient in this study due to its small sample size; therefore, larger studies are needed to reach a more definitive conclusion.

\section{Conclusions}

This clinical study examined whether droplets produced by patients wearing facial masks of various materials could contaminate a breath shield attached to a slit-lamp microscope. Contamination of the shield had slightly increased by the end of office hours on each consultation day. In contrast, no difference was observed in the level of contamination between morning and evening on closed days.

\section{Abbreviations}

COVID-19

coronavirus disease 2019

SARS-CoV-2

severe respiratory syndrome coronavirus 2

\section{Declarations}


Acknowledgments: none to declare.

Financial Disclosure: none to declare.

Conflict of Interest: none to declare.

Informed Consent: informed consent was obtained from all patients before their examination.

Author Contributions: Dr. Sato has contributed solely and in whole to this report.

Data Availability: the data supporting the findings of this study are available from the corresponding author upon reasonable request.

\section{References}

1. Muralidar S, Ambi SV, Sekaran S, Krishnan UM. The emergence of COVID-19 as a global pandemic: Understanding the epidemiology, immune response and potential therapeutic targets of SARS-CoV-2. Biochimie 2020;179:85-100.

2. Yu AY, Tu R, Shao X, Pan A, Zhou K, Huang J. A comprehensive Chinese experience against SARSCoV-2 in ophthalmology. Eye Vis (Lond) 2020;7:19.

3. Poostchi A, Kuet ML, Pegg K, Wilde C, Richardson PS, Patel MK. Efficacy of slit lamp breath shields. Eye (Lond) 2020;34(7):1185-1186.

4. Liu J, Wang AY, Ing EB. Efficacy of slit lamp breath shields. Am J Ophthalmol 2020;218:120-127.

5. Murnain KL, Ooi JL, Sharma NS. Evaluation of the slit lamp shield to reduce droplet exposure. Clin Exp Optom 2020;103(4):555-556.

6. Shah SH, Garg AK, Patel S, Yim W, Jokerst JV, Chao DL. Assessment of respiratory droplet transmission during the ophthalmic slit-lamp exam: a particle tracking analysis. Am J Ophthalmol 2021;222:76-81.

7. Ong SC, Razali MAB, Shaffiee L, Yap JX, Fei TTY, Loon SC, Koh V. Do slit-lamp shields and face masks protect ophthalmologists amidst COVID-19? Ophthalmology. 2020;127(10):1427-1429.

8. Khadia A, Nachiappan S, Kalita IR, Harsh Vardhan Singh, Rajesh Vedachalam, Rengaraj Venkatesh. Safe slit-lamp shield: maintaining a balance between ergonomics and safety. Indian J Ophthalmol 2020;68(11):2486-2489.

9. Clapp PW, Sickbert-Bennett EE, Samet JM, Berntsen J, Zeman KL, Anderson DJ, Weber DJ, et al. Evaluation of cloth masks and modified procedure masks as personal protective equipment. JAMA Intern Med 2020;e208168.

10. Ueki H, Furusawa Y, Iwatsuki-Horimoto K, Imai M, Kabata H, Nishimura H, Kawaoka Y. Effectiveness of face masks in preventing airborne transmission of SARS-CoV-2. mSphere 2020;5(5):e00637-20.

\section{Figures}




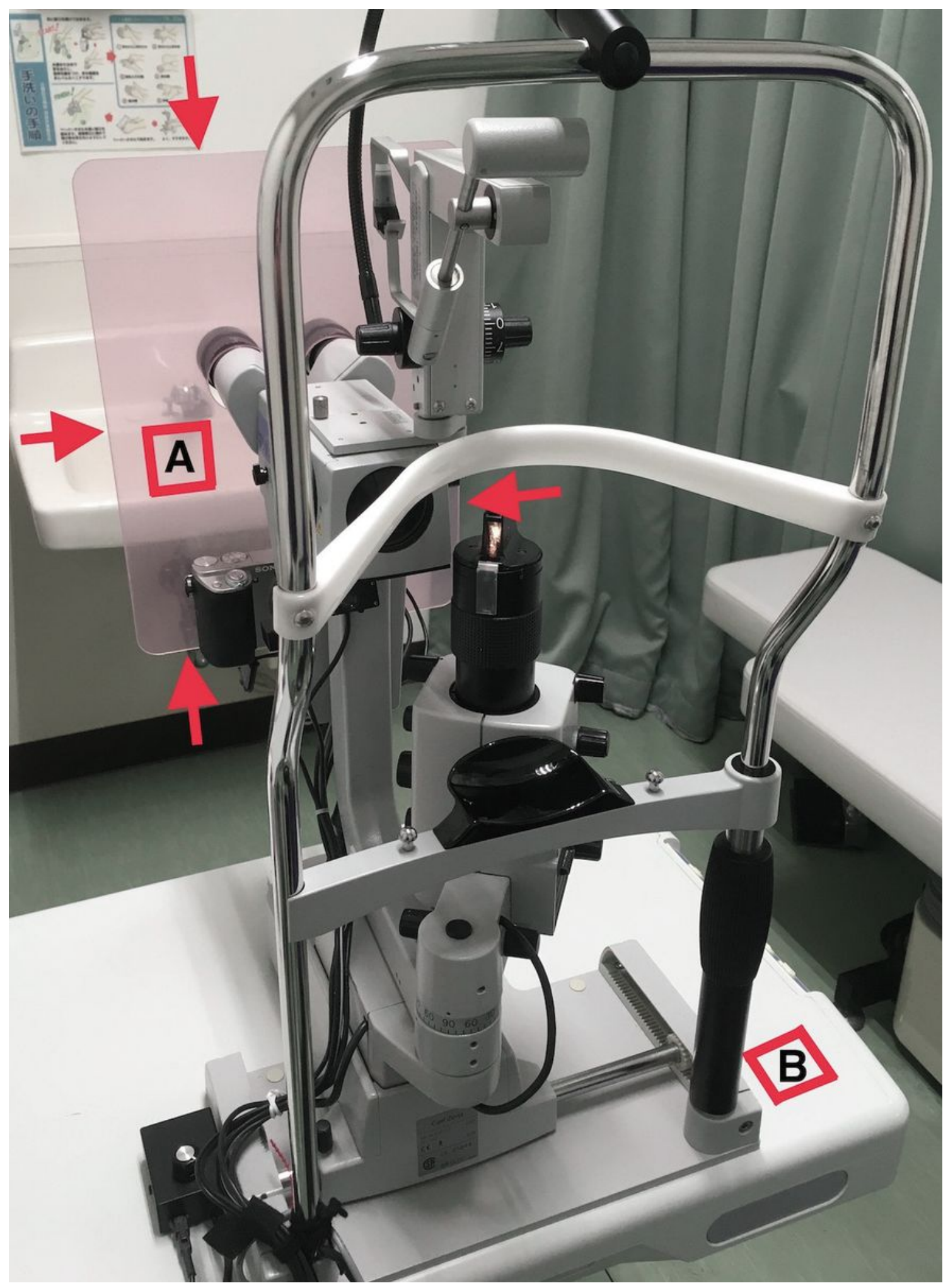

Figure 1

A breath shield (arrows) was hung on the eyepieces of a slit-lamp microscope. A measurement area of 25 square centimeters was provided on the patient-side surface of the shield $(A)$ as well as on the table (B). 